Brit. J. industr. Med., 1963, 20, 255.

\title{
THE SUCCESSFUL PREVENTION OF SILICOSIS AMONG CHINA BISCUIT WORKERS IN THE NORTH STAFFORDSHIRE POTTERIES*
}

\author{
BY \\ A. MEIKLEJOHN \\ From the Department of Industrial Health, University of Glasgow
}

(RECEIVED FOR PUBLICATION FEBRUARY 15, 1963)

The pottery industry in North Staffordshire was established towards the close of the seventeenth century. At first the wares which were made from local clays were rather crude but manufacturers unremittingly sought to improve the quality of their productions by the addition of other ingredients to the clays. In 1720 calcined powdered flint was introduced into the clay body. Six years later Benson described the serious effects of the dust on the lungs of millmen engaged in dry flint crushing. Later the disease became very prevalent not only among millmen but among workmen, males and females, in a wide range of pottery occupations and processes. Popularly the disease was known as potters' asthma or potters' rot, which was later identified scientifically as silicosis.

Among the workmen most seriously affected were men engaged in china biscuit bedding and placing and women in the china biscuit warehouse. The risk arose from bedding the ware in flint for the first or so-called biscuit firing. In the course of firing some flint adhered to the surface of pieces and this had to be scoured or brushed off to ensure a clean surface for glazing.

The manufacturers experimented to discover a suitable substitute for bedding flint. In due course it was proved that calcined alumina fulfilled all the practical requirements. This success immediately raised the question as to whether or not alumina was free from any risk to the health of workmen. The problem was investigated by a survey of furnacemen who had been seriously exposed for many years to the inhalation of alumina in the manufacture of aluminium. The research team concluded that alumina was safe. Thereafter manufacturers progressively substituted alumina for flint. At first this action was voluntary but it was made statutory in 1947.

Vigilant supervision of alumina workers in potteries and aluminium works was maintained between 1936 and 1962; the original findings as to the safety of alumina were confirmed.

During this period the firm of Doultons, where alumina was first introduced, experimented with firing china biscuit ware in tunnel ovens by a method in which the alumina is dispensed with. The method, profile placing, is now established and should in due course extend to all china manufactories.

At the end of the seventeenth century a small group of potworks was established in the moorlands above what soon became Burslem (Arnold Bennett's Bursley) the mother town of the Potteries district of North Staffordshire (Figure). The typical primitive products of this period were butter-pots, jugs, and mugs in cloudy, mottled, black and red bodies, made from local marls, and the drab-coloured salt-glazed stoneware. By mixing local clays with those imported

*The Milroy lecture delivered at the Royal College of Physicians, London, February 6, 1963. from other counties, such as Dorset, manufacturers constantly endeavoured to improve the whiteness and quality and hence the commercial value of their individual productions. The supreme aim was to discover the secrets of the composition of Chinese porcelain, which excelled in its texture and hard velvety gloss and was non-porous. To improve "the body", that is the clay mixture from which the pieces are fashioned, various sandstones pounded to grit were added to the clay. When fired this helped to render the ware less porous. The first major advance 


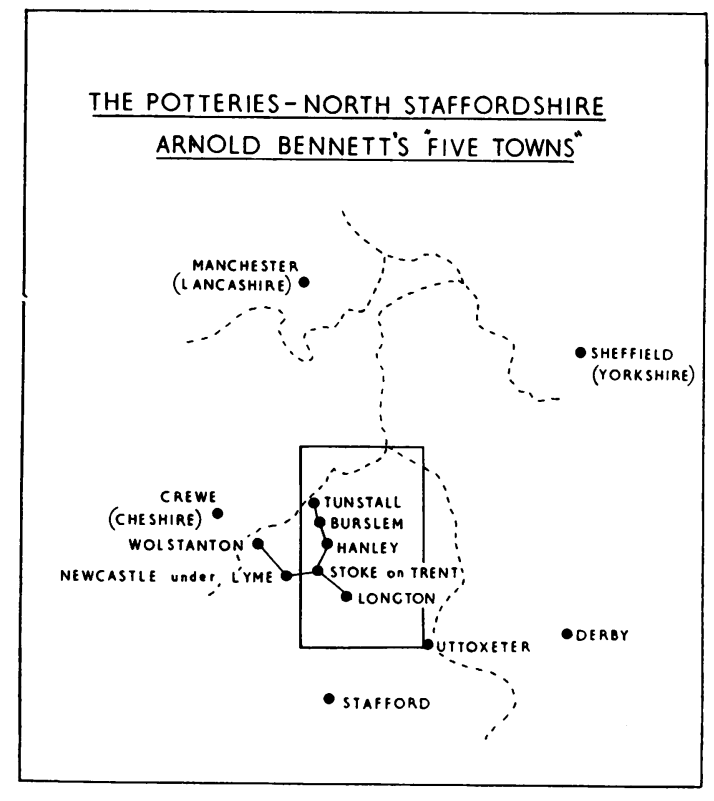

came by accident in the year 1720 (Shaw, 1829). The story runs that Thomas Astbury, a local manufacturer, was travelling to London on horseback. At Dunstable his horse seemed to be going blind and he had to seek help. The hostler at the tavern at which he stayed "burned a flint stone till quite red, then he pulverized it very fine, and by blowing a little of the dust into each eye, occasioned both to discharge much matter and be greatly benefited". Astbury observed the pure white colour of the calcined flint and the ease with which it was reduced to fine powder. He immediately conjectured that the addition of this flint to the clays might improve the whiteness of his pottery. On his return he made trials and soon gained great preference for his earthenware. Supplies of flint pebbles were obtained from the south coast around Brighton. The flints were successively washed, calcined in the ovens, pulverized in large iron mortars, and finally passed through a fine hair sieve. To keep the process secret from competitors, Astbury carried out these pulverizing operations in underground cellars, where the men were enveloped in clouds of white flint, silica dust. Six years later, in 1726, Thomas Benson, in making application for a patent for the wet grinding of flints (Meiklejohn, 1947), stated that in the existing dry method for Preparing Flints for making White Pots, "any person ever so healthfull or strong working in that business cannot probably survive above two years, occasioned by the dust sucked into his body by the air he breaths (sic)". This accorded with my own experience more than 200 years later.
Benson's is the first authentic reference to the lung disease among potters, which later was named popularly potters' rot or potters' asthma and, scientifically, silicosis.

The great English potter of this era, indeed of all times, was the celebrated Josiah Wedgwood, who commenced business on his own account at the Ivy House Works, Burslem, in 1759. In his early experiments he concentrated on improving the quality of ivory or cream-coloured earthenware. In 1765 Queen Charlotte, wife of George III, ordered a tea and coffee set of this ware and thereafter it bore the proud name "Queen's Ware" and attracted orders from all over the world. A dinner and dessert service of 952 pieces, each decorated with a different English scene, was made to the order of Empress Catherine II of Russia.

Potters at Meissen and Sèvres elucidated the secrets of oriental porcelain, which was first made in England at Chelsea in 1745 and at Worcester in 1751. In 1755 William Cookworthy of Plymouth discovered the true china clay and china stone, the equivalents of oriental kaolin and petuntze, in Cornwall. Soon afterwards in 1768 he applied for a patent to manufacture porcelain by the Chinese method. Porcelain differs from earthenware in that when fired it is vitreous (non-porous), hard, thin, and translucent; it is made from a mixture of china clay and china stone, both of which are rich in feldspar; hence the designation feldspathic china. True china is peculiarly an English product and was perfected by Josiah Spode in 1805. It is made from the same materials as porcelain but in addition bone ash obtained by calcinating ox bones is added to the extent of 50 per cent. The finished pieces are esteemed for their beautiful whiteness, delicate texture, and translucency. When sounded, china yields a characteristic ring.

\section{China Biscuit Processes}

Generally speaking, articles of domestic tableware may be classified as flat (plates and saucers) and hollow (cups and bowls). The first process is the making of the clay piece, which is then carried to a stove or greenhouse where it is kept until "green hard". The boards on which the ware is carried are liberally dusted, formerly with powdered flint, now with alumina. The purpose of dusting is to prevent the moist clay from adhering to the board. After inspection the ware is placed in fire clay containers (setters and saggars) and then set in the oven for the first or, technically, the biscuit firing. Until 30 years ago this was commonly carried out in intermittent coal-fired ovens enclosed in the bottle-shaped hovels so characteristic a feature of the Potteries landscape. 
Nowadays these ovens have been largely replaced by gas or oil-fired continuous tunnel ovens.

The biscuit firing of china, during which the temperature is advanced to about $1,250^{\circ} \mathrm{C}$., used to take 60 hours, but by the modern methods this has been reduced to 20 hours. In the course of firing, the china clay body undergoes contraction to the extent of almost one-fifth of its original size. This means that care must be taken to ensure that the shrinkage is uniform and distortion avoided. In the case of hollow ware all that is necessary is to place the saggars containing it in the least hot area of the oven and to prevent individual pieces from sticking to the saggar. This is achieved by washing the interior of the saggar with slop flint and dusting the ware with powdered flint, a process called flinting. Flat ware in the course of contracting, it was observed, tends to sag at the edge and become crooked, formerly called wauving (waving). This meant total loss, and so the need was to find some means of supporting "flat" throughout firing and cooling. For this purpose a setter, that is a fireclay container of similar shape to the piece, was devised. A soft bed of flint was prepared in the bottom of the setter, and on this the plate, saucer or dish was placed. The piece was in turn completely covered over with flint and another piece superimposed and so on until the available height was taken up. Finally all the unoccupied space was filled with flint. In the case of large expensive pieces, such as meat dishes, these were placed in individual setters. Settering was the method of choice in the manufacture of fine china. In mass-produced china, the so-called Longton trade, to save costs flat was bedded in bulk in saggars. Firstly the saggar was completely filled with pulverized flint. The placer or bedder then bedded each piece by rubbing it into the flint bed, while ensuring that all pieces were separated by a layer of the powder. Flint being highly refractory did not fuse at the firing temperatures, and as the ware contracted it was supported by its bed and so when emptied was straight.

How flint first came to be used for this purpose is not specifically recorded but possibly it simply developed from the use of sand in the placing of earthenware. Moreover, it was always at hand, cheap and clean and did not stain the ware. The bedders and flinters and their assistants were exposed to very heavy concentrations of fine powdered flint. So also were the labourers or oddmen who did the setting and drawing of the ovens and emptied the ware from the saggars. A particularly dusty process was recovering the flint by sieving it after use to remove pieces of broken ware and saggars. In the course of firing some adhered to the surface of the ware, and, to produce a clean, smooth surface for glazing, it had to be removed. This was done in the china biscuit warehouse by women who brushed and scoured it. These operatives were named collectively china biscuit warehouse workers and included china biscuit brushers and china biscuit scourers. At first these processes were carried out without any special precautions, indeed the methods included dry sandpapering. In due course extraction fans, turn-tables, and the use of respirators helped to reduce the amounts of dust inhaled. Mechanical cleaning under exhaust still further diminished the dustiness, but at best these methods were palliatives and the risk remained serious. But it was not only the process workers who suffered, indeed the dustiest occupation with the highest risk was that of flint miller or millman. These men were engaged in the calcining and dry pulverizing of bedding flint at special crushing plants. Flint is highly abrasive and so proved invaluable in removing blemishes from ware, that is polishing and grinding. In addition it was used lavishly to dust ware and boards and so was disseminated throughout the factory and into the general atmosphere of the neighbourhood.

\section{Health Problems}

Precise reference to china biscuit processes and their attendant danger was first made in the Report of the Children's Employment Commission in 1843. The delay may have been due to the fact that a comparatively small amount of china was then manufactured and the number of persons employed correspondingly few. Dr. Scriven, who, as assistant Commissioner, made the medical enquiries, reported that "phthisis is a very prevalent disease here and owes its rise and progress to the processes of scouring". He describes the processes thus:

\begin{abstract}
"When china ware is to be fired it is first placed in coarse earthen vessels called saggers (otherwise saggars)these contain a quantity of finely pulverized flint; this during the firing, attaches itself strongly to the china; some two, three or more young women are employed to scour it off with sandpaper and brushes; the particles float abundantly in the atmosphere of the room, and cover their persons just as plentifully as flour does the miller; in every act of respiration a considerable quantity is deposited on the mucous surfaces of the fauces, trachea, and bronchial tubes, and, being acutely angular and irritating, soon occasions thickening of these membranes, as evidenced by their small weak voices; asthma, chronic cough, tubercular development; consumption soon follows and death. Some of them will escape for a time whilst others become easy preys."
\end{abstract}

Between 1843 and 1845, William Evans edited a local newspaper, The Potters' Examiner and Workmen's Advocate. He never wearied in condemning 
the menace to health of lead, dust, and excessive heat in the potters' workshops. Under the pen-name Mentor he endeavoured to excite public interest through simple poems. These lines are from The Plate-Maker:

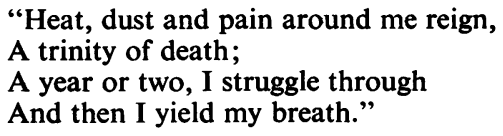

About this period dust diseases of the lungs were attracting increasing attention in a wide variety of trades, and in 1867 Zenker coined the generic name for the dust diseases of the lungs "pneumonokoniosis". In England 1856 marked the first milestone in the scientific study of these diseases. It happened in this way. St. Thomas's Hospital in that year founded a lectureship in public health in the medical and surgical college attached to the hospital. The council appointed Dr. Edward Headlam Greenhow to this office. When preparing his first course of lectures Greenhow realized for the first time, as he records, the scant and inadequate information upon which the sanitary agitation of the preceding 20 years had been based. He formed the opinion that the information collected by sanitary inquiries was unscientific and all too often inaccurate. It was unreliable to form the basis of a course of lectures for scientific students. Accordingly he felt compelled to make his own investigations. He started by making calculations of the mortality from certain groups of diseases in a number of districts for the census year 1841 , based on figures published by the Registrar General. He discovered that great differences existed between areas, and among the important influences he suspected occupation. With regard to pulmonary affections he noted that:

\footnotetext{
"The highest death-rates in both sexes occur in Staffordshire where a certain number of the population are employed in the manufacture of earthenware ... There may also be different degrees of danger in the manufacture of different kinds or qualities of earthenware. These questions could only be satisfactorily solved by a careful investigation of the subject in the pottery district."
}

Greenhow brought the results of his enquiries to the notice of Dr. (later Sir John) Simon, Medical Officer to the General Board of Health, who was so impressed that he begged Greenhow to submit the paper to the Board. Publication was made in 1858 in a volume entitled Papers Relating to the Sanitary State of the People of England, to which Simon contributed a long Introductory Report. In this he commented on the high mortality from pulmonary affections among workmen engaged in pottery manufacture. He ascribed the high mortality among male operatives to "vicissitudes of heat and cold ..." and among women to "the mechanical irritation of the lungs ... due to gritty dust caused by biscuit rubbing".

The introduction included these pearls of wisdom:

"The physical strength of a nation is no mean part of its prosperity."

and

"The sacredness of human life against unjust aggression is the principle above all others by which society subsists."

Greenhow realized the weakness of his material and remarked that some of the results would unquestionably acquire greater force and distinction if an investigation were carefully carried out in the places themselves, with the aid of that information which can only be acquired by a personal examination of places and the careful interrogation of their inhabitants.

Simon decided on behalf of the Board of Health to initiate studies of the main causes of death in separate geographical areas. In 1859 the first inspection was made on what for brevity were termed Diarrhoeal Diseases. Diseases of the Lung were selected as the problem of the year for 1860 . And so Greenhow, who was appointed to carry out the studies, emerged as the first English scientific epidemiologist, and, as proved by his work, his contributions in the occupational field were supreme.

Among the places selected for investigation into pulmonary diseases were the adjoining districts of Stoke-on-Trent and Wolstanton, in both of which the population, male and female, was largely employed in the making of earthenware and china. Greenhow's findings appeared in the Third Report of the Medical Officer of the Privy Council for the year 1860 (published in 1861).

In reference to his studies in potteries he reports:
"Placers are men who pack the ware in saggers, and afterwards place them in the oven. Earthenware is surrounded in the saggers with sand but china with flint powder. In the process of placing the latter in the saggers a considerable quantity of flint dust is said to be some- times dispersed in the atmosphere."
"China scourers remove the loose flint powder from the china after it has been baked. This is done partly by dusting or brushing, partly by rubbing the china with sand-paper, during which processes much fine dust is dispersed into the atmosphere. The fineness of the dust and its liability to remain suspended in the air, depends upon the quality of the china."
"In most potteries no special precautions are employed to prevent the dispersion of the flint dust into the atmos- phere. Biscuit scouring being the most pernicious opera- 
tion carried on in potteries, the possibility of rubbing the china in the wet state was inquired into, but it was said this would be impossible."

Just how pernicious scouring was is reflected in the experiences recounted to Greenhow at several factories. He was informed that "china scourers who continue at the occupation never fail to become asthmatical". He explains that the terms asthma and asthmatical were commonly used by miners, grinders, flax dressers, potters, and other operatives, who suffer from difficulty of breathing or cough in consequence of their occupations. He noted scourers "suffering from the advanced stage of bronchitis". Many of these women were under 30 , and the disease not infrequently terminated fatally after three to eight years in the job. He suggested that the job might be made less injurious by applying exhaust ventilation and the wearing of respirators.

The next chapter was added by the Children's Employment Commission of 1862 (First Report, 1863). The Commissioners recounted the previous reports of Scriven and Greenhow. On their behalf Mr. F. D. Longe, H.M. Inspector of Factories as assistant Commissioner, made further investigations, the results of which were the subject of a report dated January 30,1863 . He confirmed that the operation of scouring china was a very injurious employment. It was entirely carried out by women. Fortunately the number employed was not great as only a comparatively small quantity of china ware was manufactured. He makes the following significant remark: "Many young women are tempted to sacrifice their health for the high wages which this employment affords".

Among the witnesses who gave evidence to the Commission was Dr. John Thomas Arlidge, of King's College, London, who was appointed consulting physician to the North Staffordshire Infirmary in 1862. He was also appointed Certifying Surgeon for the Stoke, Fenton, and Longton districts in which the majority of the china factories were situated. Later in 1868 he became the first president of the Association of Certifying Medical Officers, now the Association of Certifying Factory Surgeons. He testified that potters as a class, both men and women, suffered excessively from lung diseases, particularly from that variety known locally as potters' asthma or potters' consumption. Throughout his life in the Potteries until his death in 1899 at the age of 77, Arlidge devoted himself to the study of potters' diseases, particularly those affecting the respiratory organs. The fruits of his unrivalled experience were presented to The Royal College of Physicians in the Milroy Lectures for 1889, entitled Occupations and Trades in Relation to Public Health. At the request of Sir Andrew Clark, president of The
Royal College of Physicians, these lectures were extended to form Arlidge's great treatise on The Hygiene, Diseases and Mortality of Occupations (1892). This volume provides extensive vital statistics of the various pottery occupations at that period. In 1864 Dr. Charles Parsons, remembered as a distinguished treasurer of the British Medical Association, who was a house surgeon at the North Staffordshire Infirmary from 1859 to 1862, presented a thesis to the University of Edinburgh On a Form of Bronchitis (simulating phthisis) which is Peculiar to Certain Branches of the Pottery Trade (Meiklejohn, 1957). For this he was awarded the degree of M.D. with Gold Medal. In the introduction he claimed that his thesis was the first published account of this "form of bronchitis" in potters. From what has been recounted this was not strictly true. The essay, however, is important for his observations on the clinical aspects of the disease and on the pathological appearances based on three necropsies. He also commented on the action of the dust in producing fibrosis, and submitted a hypothesis on the aetiology of the associated emphysema.

The first general statistical analysis of occupational mortality, based on the census year 1861 , was published in 1865 in the Supplement to the 25th Annual Report of the Registrar General. This proved to be a valuable light on health in an industrial country and so this Decennial Supplement of Occupational Mortality was continued on the figures for 1871 . This was published in 1875. Dr. William Farr, compiler of Abstracts to the General Register Office, who made the analysis, wrote:

\footnotetext{
"The earthenware manufacture is one of the unhealthiest trades in the country. At the age of joining it is low; but the mortality after the age of 35 approaches double the average; it is excessively high; it exceeds the mortality of publicans. What can be done to save the men dying so fast in the potteries and engaged in one of our most useful manufactures?"
}

Farr used the term earthenware to embrace all varieties of pottery.

In the next Report (1885) Dr. Ogle, his successor, in emphasizing the problem stated: "This excessive mortality is in greatest part due to phthisis and diseases of the respiratory organs". In 1895 Dr. Tatham continued the comments:

\footnotetext{
"According to the experience of $1890-92$ potters sustain a mortality from phthisis and respiratory diseases together which is far in excess of that experienced by any other group of workers in the list ... potters succumb to non-tubercular disease of the lungs much more rapidly than they do to phthisis; and it is certain that much of the so-called 'potters' phthisis' ought properly to be distinguished from non-tubercular cirrhosis of the lungs."
} 
The problem was included in the terms of reference of the Committee of Inquiry appointed in 1892 to inquire into and report on The Conditions of Labour in Potteries, the Injurious Effects upon the Health of the Workpeople, and the Proposed Remedies. The Committee confirmed the injurious effects of flint dust among china biscuit placers and scourers and assistants. They remarked, however, that, as the total number of flint workers was few, data suitable for statistical inferences were not collected. In reference to dust diseases attention was focused not only on the dust but on the excessive heat of the potters' shops. Among the Special Rules of 1894 which they recommended were the use of mechanical fans or other efficient ventilation, and the sweeping of floors to be done after working hours.

This coincided with the outcry against lead poisoning. In retrospect it is interesting to note how the protagonists against lead dismissed the dust problem, while others argued that the dangers of lead had been largely controlled and were fast disappearing while dust was the real and increasing enemy. This phase culminated in the Special Rules of 1898 in which women and young persons employed in china biscuit scouring were included among workmen made subject to monthly examination and suspension by the Certifying Surgeon. The operation of this scheme of examinations did not emerge until the Inquiry by the Hatch Committee appointed in 1908 (H.M.S.O., 1910). Between 1900 and 1908, 158 examinations of male young persons were made without a single suspension. In the same period 35,554 examinations were made of women, and these resulted in only eight permanent suspensions. These figures indicate a population of scourers of about 300 , almost all women. The Committee considered that, on this evidence, monthly examination was unnecessarily frequent. They recommended that the periodical interval should be one year and that the examination should be extended to include other china biscuit workers. A serious difficulty, however, presented in that the examination involved the possibility of suspension, and there was no provision for payment of workmen's compensation for pulmonary dust diseases. This foreshadowed the next steps. Meantime it appears that manufacturers were actively pursuing measures to control dust generally and in particular processes. Doulton's of Burslem evolved a system of revolving brushes under exhaust hoods for china biscuit scouring, and this method was considered so excellent that the Chief Inspector of Factories illustrated it in his Annual Report for 1899.

In conjunction with workmen employed in other dusty industries, pottery workers pressed to have fibroid phthisis, identified in 1915 by Collis as silicosis, made compensable under the Workmen's Compensation Act, 1906.

The Workmen's Compensation (Silicosis) Act, 1918 , enabled the Secretary of State to make schemes "for the payment of compensation by the employers of workmen in any specified industry or process or group of industries or processes involving exposure to silica dust". This led to a series of expert medical inquiries in dusty industries. It should be noted that such studies had been greatly facilitated by the experience of the Silicosis Medical Bureau in Johannesburg and the advances made in chest radiography. In 1926 Sutherland and Bryson, following an inquiry into the incidence of silicosis in the pottery industry, concluded:

\footnotetext{
"We are of opinion that silicosis exists in the workers in the Pottery Industry to a very considerable degree."
}

The disease appeared as a particulary serious risk among china biscuit placers and china biscuit warehouse workers. Compensation was first provided for silicosis in prescribed occupations and processes in the Pottery Industry by the Various Industries (Silicosis) Scheme, 1928.

In the Milroy Lectures, 1936, (Middleton, 1936) on Industrial Pulmonary Disease due to the Inhalation of Dust, Middleton included in his comprehensive review reference to silicosis in flint and pebble crushing and in the pottery industry. Flint processes in potteries again emerged as the most deleterious, and the estimated numbers employed were 792 males and 223 females. In the five years, 1930 to 1934 , silicosis in this population accounted for 37 male and seven female deaths, many of them in early middle life and after years of distress and suffering.

\section{Part 2. The Story of Alumina}

Workmen's compensation is a means of indemnifying the injured workman and his dependants against loss. As revealed by the original award for lead poisoning by Lord James of Hereford in 1901, it also acts as a sanction, encouraging employers to avoid claims against them by instituting and maintaining effective preventive measures. But there have always been good employers - and these are probably a majority - who have regarded good working conditions conducing to health as a duty. Of course there have been laggards among them just as there are always workmen who fail to realize that they too have a duty to keep fit and to use the means provided to safeguard the safety, health, and welfare of themselves and their workmates. Pottery manufacture is traditionally a family craft, and many businesses were founded by men who had risen from the bench. This being so, sad personal experience was often the source of attacks on the dust. This is exemplified by 
a master potter (Plant in Dymock, 1941) who played a leading part in the practical trials and education of the industry which led to the replacement of flint by alumina.

"My father died of silicosis, but they did not call it silicosis in these days, they called it asthma; he was fiftyseven years of age ... As a young man I used to work in a china factory and sometimes the dust was so thick you could almost bite it."

In $1927 \mathrm{Mr}$. H. E. Wood, works manager at The Royal Doulton Potteries, Burslem, began experimenting with materials as possible substitutes for flint in china biscuit bedding. A material to be suitable had to fulfil very rigid requirements. Primarily, it had to maintain its form practically unchanged at firing temperatures up to $1,600^{\circ} \mathrm{C}$. Also it had to be pure and not damage the ware in any way. Many materials were tried but most had to be rejected either because they fused and became solid, or failed to support the ware so that it became warped and twisted, or stained it. After many failures Wood tried alumina $\left(\mathrm{Al}_{2} \mathrm{O}_{3}\right)$ but, while promising, it produced some greenish staining. After discussions with the chief chemist of the British Aluminium Co. Ltd. alumina hydrate, $\mathrm{Al}_{2}$ $(\mathrm{OH})_{3}$, was tested. This material was first calcined in the china biscuit oven, and in this way it seems that the impurities which caused the staining were driven off. These impurities probably derived from the flux materials used in the manufacture of alumina from bauxite. The resultant powder was very fine and light and prone to trickle. Trickling meant that it left the pieces unsupported so that they became deformed and had to be rejected. This was an obstacle even in the fine china trade in which individual pieces were placed and fired in setters. It made the material completely unacceptable in the bulk "Longton china" trade in which ware for biscuit firing was bedded in bulk in saggars. To stop trickling Wood tried adding other materials and ultimately found that the addition of $3 \%$ fired and $3 \%$ raw china clay gave the best results. At length Wood and his colleagues were convinced that the medium was practicable as a substitute for flint. It was assumed that there was no disease aluminosis comparable with silicosis. Twenty years later the experience of Goralewski (1940) in Germany might have deterred them. As a mark of their complete confidence, The Royal Doulton Potteries made a complete change over from flint to alumina during the Wakes (annual summer holiday) in August, 1928. This was no simple matter that could be achieved by steps for it had been observed that if the alumina was even slightly contaminated with flint the results were bad.

The Longton manufacturers were enthusiastic to make trials. The alumina china clay mixture did not prove successful for firing in bulk in saggars. However, the idea was born, and Mr. Andrew Fotheringham, the district Inspector of Factories, became the driving force in encouraging experimental trials in every oven. He collected the results, which seemed sufficiently discouraging to justify abandonment for bulk placing; the losses, interruption of production, and delivery were too grave for an industry constantly involved in foreign competition. The experiments went on always in the hope that somehow success would come. And come it did, but remote from Longton. It fell that early in 1934 Fotheringham was bestriding his native heath playing golf in a four-ball match at Burntisland in Fifeshire. One of the players was the works chemist at the local British Aluminium Works. On March 19, 1947, Fotheringham wrote me a letter in which he recounted the critical incident which was to lead to success:

\footnotetext{
"We discussed alumina and I explained how the ware was not held straight enough. He (the chemist) said the Larne alumina used in the Potteries was different from theirs in temperature of calcination. This set me by the ears. Larne alumina owing to local plant could only be calcined to $1200^{\circ} \mathrm{C}$. whereas at Burntisland it was raised to $1600^{\circ} \mathrm{C}$."
}

On his return to Stoke Fotheringham immediately visited Mr. W. Chappell, manager at Hughes, Fenton, who had been tireless in making large trials. In due course he ran thousands of trials, often at great loss to his firm, with the new variety of calcined alumina. Together they visited nearly every china works in Longton and explained the method to the bedders and so enlisted wide co-operation. The British Aluminium Company joined in the experiments to produce a form of alumina with physical properties as nearly as possible identical with flint. To ensure that supplies of alumina delivered to them were proper, manufacturers calcined the material to $1,600^{\circ} \mathrm{C}$. in their own ovens.

As there has been considerable controversy as to who first successfully fired a large quantity of china in saggars, it should be mentioned that Mr. A. T. Finney did this in 1934, but he was fortunate at his first trial. Chappell and his firm (Hughes of Fenton), whose trials involved 20,000 pieces, were the real adventurers and deserve the credit as pioneers. Ultimately the phase of trial and error was successfully surmounted. Manufacturers who had changed over to alumina affirmed that results were so good and dependable that they would not go back to flint. Alumina, however, it had been observed, was lighter than flint and tended to fly, producing an even dustier atmosphere, and the particle size was in the dangerous respirable range. Moreover, it was gener- 
ally realized that the onset of disease of the lungs due to the inhalation of mineral dust was insidious and the manifestations often delayed for years. In this situation the manufacturers not unreasonably asked the Home Office for advice as to whether or not the use of alumina would be attended by risk of pneumoconiosis to workers exposed to it (Lancet, 1936, 2, 1478).

The Home Office referred the matter to the Medical Research Council who passed it to their Industrial Pulmonary Diseases Committee. As a result a preliminary survey of the processes in the manufacture of aluminium, in which alumina is an intermediate stage, was made at The British Aluminium Company's factories at Kinlochleven and Lochaber, Scotland. It was found that the furnacemen employed on the reduction processes were exposed to alumina dust in clouds comparable to those existing among china biscuit workers. There were 145 men who had been employed in the processes for between five and 40 years. Altogether this seemed to present an admirable field for a survey which might give sone indication of possible adverse effects among pottery workers. Dr. (now Sir Austin) Bradford Hill was invited to frame a suitable inquiry. This was arranged and consisted of three parts: (1) An investigation of sickness amongst workers in alumina; (2) a clinical and radiological examination of workers exposed to alumina dust; and (3) investigation of dust clouds. Dr. Bradford Hill himself undertook the morbidity survey and against a control group concluded that while the operatives in the reduction works experienced slightly higher sickness rates there were no really substantial differences in the pattern of sickness incidence. Dr. Charles L. Sutherland (Sutherland, Meiklejohn and Price, 1937), Chief Medical Officer of the Silicosis Medical Board, assisted by the members of the Stoke-on-Trent panel, made the clinical and radiographic examinations of the random sample of 50 workers. They concluded that "there was no evidence of pneumoconiosis or other lung disease or any adverse effects on any system or organ due to the inhalation of alumina". Mr. K. L. Goodall, H.M. Inspector of Factories, Stoke-on-Trent, who had conducted extensive dust surveys in potteries, made dust counts by thermal precipitator at both aluminium works. His report stated:

\footnotetext{
"The results indicate that the workers at the two factories visited are exposed to considerable concentration of alumina dust. The counts are definitely high compared with what we might expect for similar tests taken on china biscuit placers using powdered flint."
}

The Medical Research Council supported these conclusions (Lancet, 1936, 2, 1478).
The way was now clear: alumina was a practical medium and did not seem to involve any occupational disease hazard. With this assurance Fotheringham, who deserves to be revered as the modern counterpart of Bernard Palissy, ably backed by Mr. (later Sir Wilfrid) Garrett, H.M. Chief Inspector of Factories, and by the china manufacturers and operatives, literally did not rest from his efforts to achieve the adoption of alumina. Plant (1939) has named 1937 the annus mirabilis because it marked a significant advance towards the substitution of alumina for flint, a safe for a dangerous material. By the end of 1938, 26 firms, comprising two-thirds of the workers in the processes, out of a possible 48 firms in this branch of pottery manufacture, had made the change. Fotheringham was transferred to Leicester but his successor, Mr. Thenford Dymock, followed on with the same courage and energy. Among the manufacturers Mr. Harold Plant proved an outstanding leader. Mr. "Bert" Wood of Doulton's, who conceived the method, died on June 23,1935 , and so was not spared to see the realization of his endeavours.

Complete success was finally marked by the Pottery (Health) Special Regulations, 1947, in which it was enacted that:

"ground or powdered flint or quartz with or without the addition of other materials shall not be used in any factory to which these Regulations apply for any of the following purposes:-

(a) the placing of ware for the biscuit fire;

(b) the polishing of ware;

(c) as an ingredient in a wash for saggars, trucks, bats, cranks or other articles used in supporting ware during firing;

(d) as dusting or supporting powder in potters' shops."

So alumina replaced flint not merely in placing but in all china processes and extended to the polishing of earthenware. Flint pulverizers benefited by not having to calcine and crush flint for china factories. And the lethal flint ceased to be ubiquitous in the china pot-banks. Furthermore flint was prohibited as a "parting" powder in other industries, for example, foundries.

Doctors dealing with the pneumoconioses can never forget that the onset of the disease is insidious and that the price of safety is eternal vigilance. So in 1946 the Silicosis Medical Board at Stoke-on-Trent followed up the furnacemen examined at Kinlochleven and Lochaber in 1936 (Meiklejohn and Jones, 1948). Six had died but none from respiratory disease, and the original conclusions still seemed valid. As to the china biscuit workers who had worked exclusively with alumina in the period 1928 to 1946 , none showed any deleterious effects. When flint was the medium the china biscuit workers were 
pale, often haggard and listless (Milroy's cachexia), but now they appeared natural in complexion, robust, and active. In their daily work they were happy and contented; the fear of the dust had gone.

A constant check on respiratory diseases among pottery workers was instituted and maintained by the Mass Radiography Service, Stoke-on-Trent, under Dr. E. Posner. A special survey of china biscuit workers was made between 1952 and 1954. The results accorded with previous experience; all cases of pneumoconiosis which were detected had worked in flint for material periods or had been exposed to other varieties of harmful dust in the pottery industry or elsewhere. Not a single case gave rise to suspicion that alumina per se had produced any adverse effect. Another survey by Posner in 1956 (Meiklejohn and Posner, 1957) re-affirmed these findings.

Finally in 1961 enquiries were addressed to the following authorities who have been intimately associated with the problem during the 33 years, 1928-1961: (1) Pottery manufacturers; (2) National Society of Pottery Workers; (3) H.M. Inspectors of Factories; (4) Pneumoconiosis Medical Panels at Stoke-on-Trent and Glasgow; (5) Mass Radiography Unit, Stoke-on-Trent; and (6) British Aluminium Company Limited. Not one of these had knowledge of a single case of pneumoconiosis among workmen exposed to alumina dust, nor had they any evidence that it had caused injury to health. That is the conclusion after 30 years of watchfulness. There may still be sceptics so it is reassuring to be able to announce that as a result of recent experiments by Mr. R. Bentley, manager at Doulton's, Burslem, a new method of china biscuit placing (profile placing), in which the alumina is dispensed with, is now in use at the factory and will in time be introduced into other china manufactories. This is the consummation so devoutly wished, for all dust is dangerous and wasteful.
The preparation of these lectures has extended over 30 years. It is a pleasure to record my gratitude to all who have assisted and collaborated with me throughout this period. A special measure of thanks is due to the directors and managers of The Royal Doulton Potteries, Burslem, to a long line of Inspectors of Factories at Stoke-onTrent, to my secretary, Miss I. B. Meikle, and to all pottery workers in North Staffordshire.

\section{REFERENCES}

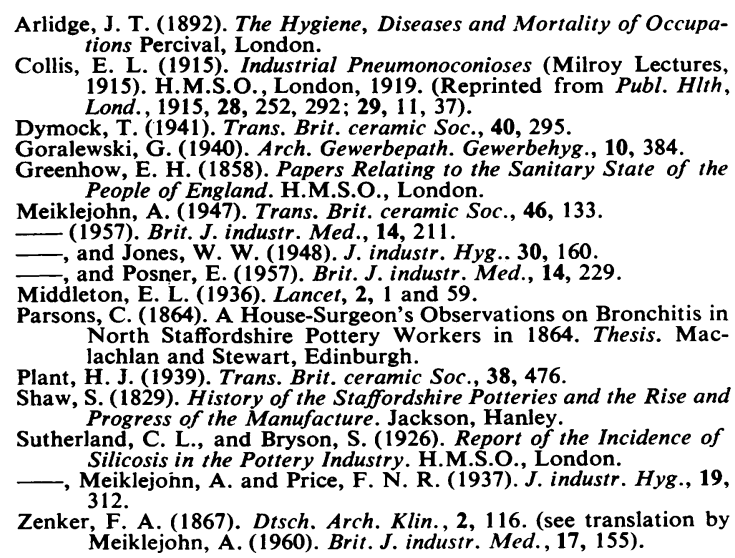

Arlidge, J. T. (1892). The Hygiene, Diseases and Mortality of Occupations Percival, London.

Collis, E. L. (1915). Industrial Pneumonoconioses (Milroy Lectures, 1915). H.M.S.O., London, 1919. (Reprinted from Publ. Hlth, Lond., 1915, 28, 252, 292; 29, 11, 37).

Dymock, T. (1941). Trans. Brit. ceramic Soc., 40, 295.

Gymock, T. (1941). Trans. Brit. ceramic Soc., 40, 295.

Goralewski, G. (1940). Arch. Gewerbepath. Gewerbehyg., 10, 384. People of England. H.M.S.O., London.

Meiklejohn, A. (1947). Trans. Brit. ceramic Soc., 46, 133.

(1957). Brit. J. industr. Med., 14, 211.

, and Jones, W. W. (1948). J. industr. Hyg.. 30, 160.

- and Posner, E. (1957). Brit. J. industr. Med., 14, 229

Middleton, E. L. (1936). Lancet, 2, 1 and 59.

Parsons, C. (1864). A House-Surgeon's Observations on Bronchitis in North Staffordshire Pottery Workers in 1864. Thesis. Maclachlan and Stewart, Edinburgh.

Plant, H. J. (1939). Trans. Brit. ceramic Soc., 38, 476.

Shaw, S. (1829). History of the Staffordshire Potteries and the Rise and Progress of the Manufacture. Jackson, Hanley.

Progress of the Manufacture. Jackson, Hanley.
Sutherland, C. L., and Bryson, S. (1926). Report of the Incidence of

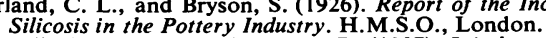

-, Meiklejonn, A. and Price, F. N. R. (1937). J. industr. Hyg., 19, 312.

Zenker, F. A. (1867). Dtsch. Arch. Klin., 2, 116. (see translation by Meiklejohn, A. (1960). Brit. J. industr. Med., 17, 155).

Reports

Children's Employment Commission (1843). Second Report of the Commissioners Trades and Manufactures. H.M.S.O., London.

Third Report of the Medical Officer of the Privy Council (1860) London, 1861.

Children's Employment Commission (1862). First Report of the Commissioners with Appendix. H.M.S.O., London. 1863.

Manufacture of China and Earthenware (1893). Report on The Conditions of Labour in Potteries, The Injurious Effects upon the Health of the Workpeople, and the Proposed Remedies. Health of the W.S.O., London.

Report of the Departmental Committee of Lead, Dust and Other Causes in the Manufacture of Earthenware and China with Appendices in the Manufacture of Earthenware and China with Appendices
and Minutes of Evidence (1910). H.M.S.O., London. Cd. 5219, and Minutes of

Annual Reports of H.M. Chief Inspector of Factories and (Workshops) (1892, continued). H.M.S.O., London.

Farr, W. (1875). Supplement to the Thirty-Fifth Annual Report of the Registrar General. H.M.S.O., London (C.-1155-I).

Note

The original typescripts, extensive notes, excerpts from the literature, photostats, and reprints were bound in a volume entitled Anthology-Milroy Lectures, 1963. This was presented to the library of The Royal College of Physicians. A collection of mounted pathological specimens with accompanying radiographs illustrating silicosis in the china bedding and associated processes was presented to the museum of The Royal College of Physicians. 